\title{
ICT, R\&D AND ORGANIZATIONAL INNOVATION: EXPLORING COMPLEMENTARITIES IN INVESTMENT AND PRODUCTION
}

\author{
Pierre Mohnen \\ Michael Polder \\ George van Leeuwen \\ Working Paper 25044 \\ http://www.nber.org/papers/w25044 \\ NATIONAL BUREAU OF ECONOMIC RESEARCH \\ 1050 Massachusetts Avenue \\ Cambridge, MA 02138 \\ September 2018
}

The views expressed in this paper are those of the authors and do not reflect any policy stance by Statistics Netherlands. We thank for their comments Eric Bartelsman, Emmanuel Duguet, Bronwyn Hall, Jonathan Haskel, Jacques Mairesse, Stephane Robin, Nicolas van Zeebroeck, and the participants at various workshops. Errors are our own. The views expressed herein are those of the authors and do not necessarily reflect the views of the National Bureau of Economic Research.

NBER working papers are circulated for discussion and comment purposes. They have not been peer-reviewed or been subject to the review by the NBER Board of Directors that accompanies official NBER publications.

(C) 2018 by Pierre Mohnen, Michael Polder, and George van Leeuwen. All rights reserved. Short sections of text, not to exceed two paragraphs, may be quoted without explicit permission provided that full credit, including $\odot$ notice, is given to the source. 
ICT, R\&D and Organizational Innovation: Exploring Complementarities in Investment and Production

Pierre Mohnen, Michael Polder, and George van Leeuwen

NBER Working Paper No. 25044

September 2018

JEL No. L25,O30,O33

\begin{abstract}
$\underline{\text { ABSTRACT }}$
This paper examines whether there are complementarities between investments in ICT, R\&D and organizational innovation, and the effects of different investment profiles on total factor productivity growth on Dutch firm-level data. We estimate an integrated model of investment profile adoption and total factor productivity growth. We find that the three investment decisions are complementary, in the sense that investing in one increases the probability of investing in another one because joint investments lead to higher TFP growth than individual investments. ICT earns on average an expected rate of return of $9.7 \%$, followed by $6 \%$ to $7 \%$ on organizational innovation and a modest $1.4 \%$ to $1.8 \%$ on $\mathrm{R} \& \mathrm{D}$ in services and manufacturing respectively.
\end{abstract}

Pierre Mohnen

UNU-MERIT

Maastricht University

P.O. Box 616

6200 MD Maastricht

Netherlands

p.mohnen@maastrichtuniversity.nl

Michael Polder

CBS/ Statistics Netherlands

P.O. Box 24500

2490 HA The Hague, The Netherlands

jmpolder@gmail.com
George van Leeuwen

CBS

P.O. Box 24500

2490 HA The Hague, The Netherlands

georgevanleeuwen@hetnet.nl 


\section{Introduction}

In the eyes of most historians of science and technology, the information and communication technology (ICT) can be classified among general purpose technologies (GPT) such as the wheel, steam power, combustion engine and electricity (Lipsey, Carlaw and Bekhar, 2005; Jovanovic and Rousseau, 2005; Brynjolfsson and McAfee, 2014). It took some time before ICT showed up in the productivity statistics, but by now it is common to distinguish between ICT and non-ICT capital in productivity analysis, and a great deal of economic and labor productivity growth in the last 30 years has been ascribed to ICT capital deepening (Jorgenson et al. 2008). Even skeptics have acknowledged the transformational power of digital technology, although they claim that the economic benefits are short-lived, and that the impact of ICT does not stand up to that of earlier GPTs (e.g. Gordon, 2016).

Another channel through which ICT affects labour productivity growth is through its potential impact on total factor productivity (TFP). One explanation for the differential success of ICT capital in fostering productivity has been the argument of complementarity between ICT investment and investment in intangible assets, such as organizational capital (Brynjolfsson and Saunders, 2010; Bresnahan, Brynjolfsson and Hitt, 2002). Firms need to reorganize their way of operating to benefit from the digital technology, and vice versa. ${ }^{1}$

But beyond its contribution to TFP via organizational change, ICT can also increase the returns to R\&D, generating a string of new technological innovations. It can also make R\&D more effective in the sense that it facilitates the gathering, documenting, and sharing of knowledge and information. Besides the potential to improve research effectiveness, these characteristics of ICT can also improve the possibility and quality of collaboration between researchers.

In this paper, we look at the triangle between ICT, technological and non-technological innovation. In particular, we look at $R \& D$ as an instance of technological innovation, and organizational change as a non-technological innovation. Parts of this triangle and its relation to productivity have been covered extensively in the literature. Putting the pieces together in one framework is a novelty of our analysis. We shall reassess the contribution of ICT to TFP growth and reexamine the hypothesis of complementarity between organizational innovation and ICT. In addition, we shall explore whether the returns to ICT and R\&D are mutually reinforcing, in the sense that innovation is ICT-facilitated and, vice versa, that the returns from ICT stem in part from the generation of knowledge.

The paper is structured as follows. In section 2, we briefly review the literature on the role of ICT and R\&D for productivity, on the complementarity between ICT and organizational innovation and on the GPT aspects of ICT. Section 3 is devoted to modeling aspects. In section

\footnotetext{
${ }^{1}$ At the aggregate level, network and spillover effects can arise, and digital technology may improve the allocation of resources (Syverson, 2010).
} 
4 we describe the data and the main variables. In section 5 we present the estimation results and in section 6 we conclude.

\section{The literature}

A vast literature has documented evidence on different determinants of productivity, both at the macro- and at the micro-level (see Syverson, 2010). Among the determinants, investment in information and communication technology (ICT) and the generation of knowledge feature prominently.

One strand of the literature has estimated the returns (private and social) to R\&D and the contribution of R\&D to total factor productivity (TFP) or economic growth following the seminal work by Griliches, 1979, and with some recent advances by Doraszelski and Jaumandreu (2013) (see e.g. Hall, Mairesse and Mohnen, 2010, for a review of the literature). Another branch has related R\&D to innovation, and innovation to productivity, the workhorse model being the CDM model as proposed by Crépon, Duguet and Mairesse (1998); see Mairesse and Mohnen (2010) for an overview. Neither line of research considers the complementarity with ICT, although recently Polder, van Leeuwen, Mohnen and Raymond (2010) and Hall, Lotti and Mairesse (2013) model R\&D and ICT investment as input into innovation, defined as product, process and organizational innovation.

In parallel, many studies have investigated the effect of the adoption of ICT equipment on economic performance (see e.g. Stiroh, 2010), without an explicit role for R\&D. Some studies have used aggregate or sectoral data, others have used firm data. The studies that use macro or sectoral data have mainly analyzed the effect of ICT or R\&D on productivity within a growth accounting framework (see Draca, Sadun and van Reenen 2007, Biagi, 2013 for reviews of the literature), but not so much the complementarity between ICT and R\&D in raising productivity.

A substantial effort has been made to measure the stocks of intangibles, including R\&D but also software, databases and organizational capital, and to assess their importance in (corrected) cross-country GDP growth (Corrado, Hulten and Sichel, 2009; Corrado, Haskel, JonaLasinio and Iommi, 2013). These industry-level data are beginning to be used to explore complementarities between different types of assets. Chen, Niebel and Saam (2014) and Corrado, Haskel and Jona-Lasinio (2017) find evidence of a positive direct effect of ICT on TFP, as well as a significant indirect effect through its interaction with intangibles. Using EUKLEMS data, Pieri, Vecchi and Venturini (2017) explore complementarities between ICT and $R \& D$ in reducing technical inefficiencies.

The empirical studies that have been conducted on the hypothesis of complementarity between ICT and organizational change are mainly based on micro data (Bresnahan et al., 2002; Black and Lynch, 2001; Caroli and Van Reenen, 2001; Crespi et al., 2007; Van Reenen et al., 2010; Riley and Vahter, 2013). The available econometric evidence shows that a combination 
of investment in ICT and changes in organization and work practices facilitated by these technologies contributes to firms' productivity growth. Case studies reveal that the introduction of information technology is combined with a transformation of the firm, investment in intangible assets, and a change in the relation with suppliers and customers. Electronic procurement, for instance, increases the control over inventories and decreases the costs of coordinating with suppliers. In addition, ICT offers the possibility for flexible production: just-intime inventory management, enterprise resource planning, et cetera.

Whereas there is a lot of empirical backing at the firm level for the complementarity between ICT and organizational innovation, there is less evidence of a complementarity between R\&D and ICT or between ICT and technological innovations in the form of new products or processes. Hall, Lotti and Mairesse (2013) on Italian data, Rybalka (2015) on Norwegian data and Aboal and Tacsir (2018) on Uruguyan data find no conclusive evidence in favour of either a complementarity or a substitutability between R\&D and ICT. Many studies have investigated the role of ICT in fostering R\&D or innovation, however. For German firm data, Cerquera and Klein (2008) find that ICT is associated with an increase in in the variation of productivity, and that this process of creative destruction gives incentives for firms to invest in R\&D. Also for Germany, Engelstätter (2012) finds that different types of software have a positive effect on product and process innovation, and moreover that there is complementarity between software and organizational practices in their effect on innovative performance. Polder et al. (2010) find that ICT investment is important for all types of innovation in services, while it plays a limited role in manufacturing, while Kleis, Chwelos, Ramirez and Cockburn (2012) find that investments in information technology increase innovation output measured by patents. Van Leeuwen and Farooqui (2008) show that e-sales and broadband use affect productivity significantly through their effect on innovation output. Finally, Forman and van Zeebroeck (2012) find that internet connections increase collaborative research, but not the productivity of lone researchers or of researchers located close to each other. In contrast, Spiezia (2011) concludes from an OECD-led international comparison study on firm data that ICT usage does not increase the probability to come up with a new innovation developed in-house.

In addition, a related line of research looks at complementarities between different types of innovation or different types of ICT. Miravete and Pernías (2006) and Martínez-Ros and Labeaga (2009) for instance find complementarity between product and process innovation by looking at the adoption decision. This result is confirmed in Polder et al. (2010) who look at the production function. This latter study also finds that product and organizational innovation are complements, while process and organizational innovation are found to be substitutes. For ICT, following an approach methodologically close to ours, Kretschmer, Miravete and Pernías (2012) find that different types of software are substitutes in production. The results of Bartelsman, van Leeuwen and Polder (2017), however, point to complementarity as well as substitutability, depending on the types of software considered. 
In our paper we will address the triangle of complementarity between ICT (hardware), R\&D and organizational change, by looking at the joint firm-level binary investment decisions together with their productivity effects.

\section{Model}

While it is true that ICT and R\&D can be considered as inputs in the innovation process, ICT for sure, but even R\&D, have also a direct role to play in the production function besides affecting innovation. Therefore, in contrast to Polder et al. (2010), Hall et al. (2012) and Rybalka (2015) we do not resort to a CDM type of model (Crépon, Duguet, and Mairesse, 1998), with a knowledge production function combined with a usual production function. Instead, we shall model ICT, R\&D and organizational innovation as binary choices with simultaneous feedback effects. That is, when two strategies are complements in the sense that doing one increases the returns of doing the other one (Milgrom and Roberts, 1990), the returns from adoption (and therefore the adoption decisions) are mutually dependent.

In our model, firms choose combinations of investments (c.q. 'investment profiles') based on their (ex-ante) expected returns in terms of productivity growth. When multiple investments are involved, there is a 'complementarity bonus' (or 'substitutability penalty') added to the return on the individual investment. Given the simultaneous modelling of the productivity equation, the ex-post effects of the investments on productivity growth will be consistent with the ex-ante expected returns which led to that specific combination of investments. We thus model complementarities in terms of an objective function (the PROD approach) where the strategy choices (or investments) are themselves endogenous, as recommended by Athey and Stern (1998).

Modelling the direct effect of ICT and R\&D on productivity, brings our analysis also closer to the literature on intangibles and growth accounting using industry-level data (Corrado, Hulten and Sichel, 2009), where R\&D and ICT are considered as separate types of capital. Also in conformity with the introduction of stocks of intangibles in the production function as in Corrado et al. (2009) we consider it more appropriate that investment affects the growth rather than the level of total factor productivity. The productivity levels depend on the stocks of knowledge, organizational capital and ICT capital. The productivity growth rates, instead, depend on the increases in these stocks. We do not model the choice of the investment levels, only the binary choices as to whether investments in ICT, R\&D and organizational innovations are made. ${ }^{2}$

\footnotetext{
${ }^{2}$ It may be argued that the strategy choices are made on the basis of another objective function than total factor productivity growth, and that therefore, as well as for reasons of limited managerial foresight or unforeseen developments, there may be a difference between ex-ante and ex-post complementarity.
} 


\subsection{Investment stage}

In order to test for the presence of complementarity between innovation strategies, in particular between investing in ICT, R\&D and organizational innovation, we first consider the adoption approach, i.e. the detection of joint use of strategies for reasons other than correlations in unobserved determinants (Milgrom and Roberts, 1990; Athey and Stern, 1998). This approach is close to that of Miravete and Pernías (2006), and was also applied in Bartelsman et al. (2017) and Van Leeuwen and Mohnen (2017).

Consider an objective function that depends on the realization of the combination of strategies, so called states. The contribution to the objective function achieved by the adoption of each individual strategy $O_{i t}^{j}$ is given by the following expression

$O_{i t}^{j}=\left(\beta_{j}^{\prime} x_{i t}^{j}+\sum_{k \neq j}\left(\alpha_{j k} / 2\right) y_{i t}^{k}+\varepsilon_{i t}^{j}\right) y_{i t}^{j}$

For reasons of identification, $\alpha_{j k}=\alpha_{k j}$. The "return" from the adoption of strategy $j$ depends on exogenous variables $x_{i t}^{j}$, which may be strategy specific, the adoption of the other strategies $y_{i t}^{k}$ and a random error term $\varepsilon_{i t}^{j}$. The error terms are assumed to be jointly normally distributed with unitary variances (for reasons of identification) but non-zero covariances. The dependence on the adoption of other strategies makes this a simultaneous model, in which the choice of strategies is endogenously determined. This allows us to test for potential complementarity at the investment stage, in the sense that firms adopt a combination of strategies which they think will be beneficial.

The total level of the objective, which will be left unspecified for now but modelled in section 3.2 as the contribution to total factor productivity (TFP) growth, is given by

$T O_{i t}=\sum_{j} O_{i t}^{j}$

As shown by Lewbel (2007), this way of writing the objective function avoids any incoherency and incompleteness problem, i.e. guarantees the existence and uniqueness of the endogenous dummy variables for any given realization of the exogenous variables.

Let us illustrate the model by working with two strategies denoted as $y^{j} \in\{0,1\}, j=1$, 2. For example, if state $(1,1)$ is chosen, where the first position refers to strategy $y^{1}$ and the second position to strategy $y^{2}$, then the contribution to TFP growth is given by

$T O_{i t}(1,1)=\beta_{1}^{\prime} x_{i t}^{1}+\alpha_{12}+\beta_{2}^{\prime} x_{i t}^{2}+\varepsilon_{i t}^{1}+\varepsilon_{i t}^{2}{ }^{3}$

The coefficient $\alpha_{12}$ captures the complementarity (if positive) or substitutability (if negative) between the pair of strategies. For every combination of strategies we can compute the value of the objective function. To estimate the parameters of the model we write down the proba-

\footnotetext{
${ }^{3}$ Notice that $\alpha_{12}=\alpha_{21}$ in equation (3) corresponds to $\alpha_{12} / 2+\alpha_{21} / 2$ in the notation of equation (1).
} 
bility of every possible state. For instance, the probability that strategy 1 and strategy 2 are chosen, denoted as state $(1,1)$, is derived from the upper and lower bounds of the distribution of the error terms given that the value of the objective function under $(1,1)$ must be higher than under any pair of strategies:

$$
\begin{aligned}
& T O_{i t}(1,1)>T O_{i t}(0,0) \Rightarrow \beta_{1}^{\prime} x_{i t}^{1}+\alpha_{12}+\beta_{2}^{\prime} x_{i t}^{2}+\varepsilon_{i t}^{1}+\varepsilon_{i t}^{2}>0 \\
& T O_{i t}(1,1)>T O_{i t}(1,0) \Rightarrow \beta_{2}^{\prime} x_{i t}^{2}+\alpha_{12}+\varepsilon_{i t}^{2}>0 \\
& T O_{i t}(1,1)>T O_{i t}(0,1) \Rightarrow \beta_{1}^{\prime} x_{i t}^{1}+\alpha_{12}+\varepsilon_{i t}^{1}>0 .
\end{aligned}
$$

State $(1,1)$ is therefore associated to the following area of the distribution of the error terms:

$\varepsilon_{i t}^{1}>-\left(\beta_{1}^{\prime} x_{i t}^{1}+\alpha_{12}\right)$

$\varepsilon_{i t}^{2}>\max \left(-\left(\beta_{2}^{\prime} x_{i t}^{2}+\alpha_{12}\right),-\left(\beta_{1}^{\prime} x_{i t}^{1}+\alpha_{12}+\beta_{2}^{\prime} x_{i t}^{2}+\varepsilon_{i t}^{1}\right)\right)$

where (5.1) follows directly from (4.3), and (5.2) follows from combining (4.1) and (4.2) while conditioning on $\varepsilon_{i t}^{1}$. The same reasoning can be applied to derive the adoptions for the other states.

State $(1,0)$ is adopted when

$$
\begin{aligned}
& T O_{i t}(1,0)>T O_{i t}(0,0) \Rightarrow \beta_{1}^{\prime} x_{i t}^{1}+\varepsilon_{i t}^{1}>0 \\
& T O_{i t}(1,0)>T O_{i t}(0,1) \Rightarrow \beta_{1}^{\prime} x_{i t}^{1}+\varepsilon_{i t}^{1}>\beta_{2}^{\prime} x_{i t}^{2}+\varepsilon_{i t}^{2} \\
& T O_{i t}(1,0)>T O_{i t}(1,1) \Rightarrow \beta_{2}^{\prime} x_{i t}^{2}+\alpha_{12}+\varepsilon_{i t}^{2}<0
\end{aligned}
$$

In other words, when $\varepsilon_{i t}^{1}>-\beta_{1}^{\prime} x_{i t}^{1}$ and

$$
\varepsilon_{i t}^{2}<\min \left(-\left(\beta_{2}^{\prime} x_{i t}^{2}+\alpha_{12}\right),\left(\beta_{1}^{\prime} x_{i t}^{1}-\beta_{2}^{\prime} x_{i t}^{2}+\varepsilon_{i t}^{1}\right)\right)
$$

State $(0,1)$ is adopted when

$$
\begin{aligned}
& T O_{i t}(0,1)>T O_{i t}(0,0) \Rightarrow \beta_{2}^{\prime} x_{i t}^{2}+\varepsilon_{i t}^{2}>0 \\
& T O_{i t}(0,1)>T O_{i t}(1,0) \Rightarrow \beta_{2}^{\prime} x_{i t}^{2}+\varepsilon_{i t}^{2}>\beta_{1}^{\prime} x_{i t}^{1}+\varepsilon_{i t}^{1} \\
& T O_{i t}(0,1)>T O_{i t}(1,1) \Rightarrow \beta_{1}^{\prime} x_{i t}^{1}+\alpha_{12}+\varepsilon_{i t}^{1}<0
\end{aligned}
$$

In other words, when $\varepsilon_{i t}^{1}<-\left(\beta_{1}^{\prime} x_{i t}^{1}+\alpha_{12}\right)$ and

$$
\varepsilon_{i t}^{2}>\max \left(-\left(\beta_{2}^{\prime} x_{i t}^{2}\right), \beta_{1}^{\prime} x_{i t}^{1}-\beta_{2}^{\prime} x_{i t}^{2}+\varepsilon_{i t}^{1}\right)
$$

State $(0,0)$ is adopted when

$$
T O_{i t}(0,0)>T O_{i t}(1,0) \Rightarrow \beta_{1}^{\prime} x_{i t}^{1}+\varepsilon_{i t}^{1}<0
$$


$T O_{i t}(0,0)>T O_{i t}(0,1) \Rightarrow \beta_{2}^{\prime} x_{i t}^{2}+\varepsilon_{i t}^{2}<0$

$T O_{i t}(0,0)>T O_{i t}(1,1) \Rightarrow \beta_{1}^{\prime} x_{i t}^{1}+\beta_{2}^{\prime} x_{i t}^{2}+\alpha_{12}+\varepsilon_{i t}^{1}+\varepsilon_{i t}^{2}<0$

In other words, when $\varepsilon_{i t}^{1}<-\beta_{1}^{\prime} x_{i t}^{1}$ and

$$
\varepsilon_{i t}^{2}<\min \left(-\beta_{2}^{\prime} x_{i t}^{2},-\left(\beta_{1}^{\prime} x_{i t}^{1}+\beta_{2}^{\prime} x_{i t}^{2}+\alpha_{12}+\varepsilon_{i t}^{1}\right)\right)
$$

As shown in Miravete and Pernías (2006), when $\alpha_{12}=0$, the subdivision of the space of $\left(\varepsilon_{i t}^{1}, \varepsilon_{i t}^{2}\right)$ is the same as for the bivariate probit. When $\alpha_{12}>0$, the states $(1,1)$ and $(0,0)$ are defined over a larger region of that error space, and if $\alpha_{12}<0$, the states $(1,0)$ and $(0,1)$ are defined over a smaller region of that error space.

\subsection{Productivity growth equation}

Going one step further, the return from each investment profile can be measured in terms of productivity growth. The objective, which was very general and unspecified in equation (2), is then explicitly specified. In this way we integrate the strategy adoption equations with the productivity growth equation. This is what Kretschmer, Miravete and Pernías (KMP, 2012) have done in combining the "adoption approach" and the "productivity approach" of complementarity in the words of Athey and Stern (1998). Like them, we distinguish between observed and unobserved determinants of innovation, hence firms may adopt different strategies even if the observed determinants are the same. We differ from KMP (2012) in that we do not use economic profits but productivity growth rates. Instead of combining dichotomous data on two types of software innovation with continuous variables on scale and profit, which depend on the innovation choices, we combine three dichotomous innovation indicators (ICT, $\mathrm{R} \& \mathrm{D}$ and organizational innovation) with productivity growth rates that depend on the choice of investments. Another difference is that instead of maximizing a likelihood function with analytical conditional distributions, an expression which becomes more tedious to derive as the number of equations increases, we work with simulated conditional likelihoods.

To that effect we shall estimate a total factor productivity growth equation, which depends on the chosen investment profiles. TFP growth is the portion of output growth that is not explained by the growth rates in the traditional inputs, labor and capital. In the case of two strategies, TFP growth would be given by the following expression:

$T \dot{F P} P_{l t}=\gamma_{t}+T O_{i t}=\gamma_{t}+\left(\beta_{1}^{\prime} x_{i t}^{1}+\varepsilon_{i t}^{1}\right) y_{i t}^{1}+\left(\beta_{2}^{\prime} x_{i t}^{2}+\varepsilon_{i t}^{2}\right) y_{i t}^{2}+\alpha_{12} y_{i t}^{1} y_{i t}^{2}+\varepsilon_{i t}^{3}$

where $\gamma_{t}$ represents disembodied technical change and $\varepsilon_{i t}^{3}$ represent unobservable determinants of TFP growth.

$T F P_{l t}$ can take four values depending on the realizations of the error terms $\varepsilon_{i t}^{1}$ and $\varepsilon_{i t}^{2}$ :

- State (1,1): $\gamma_{t}+\beta_{1}^{\prime} x_{i t}^{1}+\alpha_{12}+\beta_{2}^{\prime} x_{i t}^{2}+\varepsilon_{i t}^{1}+\varepsilon_{i t}^{2}+\varepsilon_{i t}^{3}$ in the region defined by (5.1) and (5.2) 
- $\quad$ State (1,0): $\gamma_{t}+\beta_{1}^{\prime} x_{i t}^{1}+\varepsilon_{i t}^{1}+\varepsilon_{i t}^{3}$ in the region defined by (7.1) and (7.2)

- $\quad$ State (0,1): $\gamma_{t}+\beta_{2}^{\prime} x_{i t}^{2}+\varepsilon_{i t}^{2}+\varepsilon_{i t}^{3}$ in the region defined by (9.1) and (9.2)

- $\quad$ State $(0,0): \gamma_{t}+\varepsilon_{i t}^{3}$ in the region defined by (11.1) and (11.2).

If we assume the random vector $\left[\varepsilon_{i t}^{1}, \varepsilon_{i t}^{2}, \varepsilon_{i t}^{3}\right]^{\prime}$ to be normally distributed with mean 0 and variance-covariance matrix $\Omega$, then the likelihood function associated with the observed choices of strategies and the observed values of TFP growth is given by

$$
\begin{aligned}
\mathcal{L}=\prod_{i, t} f_{1}\left(T \dot{F} P_{l t}\right. & \left.-\left(\gamma_{t}+\left(\beta_{1}^{\prime} x_{i t}^{1}+\varepsilon_{i t}^{1}\right) y_{i t}^{1}+\left(\beta_{2}^{\prime} x_{i t}^{2}+\varepsilon_{i t}^{2}\right) y_{i t}^{2}+\alpha_{12} y_{i t}^{1} y_{i t}^{2}\right) \mid \varepsilon_{i t}^{1}, \varepsilon_{i t}^{2}\right) \\
& \times F_{2}\left(\varepsilon_{i t}^{1}, \varepsilon_{i t}^{2}\right)
\end{aligned}
$$

where $f_{1}\left(. \mid \varepsilon_{i t}^{1}, \varepsilon_{i t}^{2}\right)$ is the (conditional) univariate normal density function of $\varepsilon_{i t}^{3}$ conditional on values of $\varepsilon_{i t}^{1}$ and $\varepsilon_{i t}^{2}$, and $F_{2}\left(\varepsilon_{i t}^{1}, \varepsilon_{i t}^{2}\right)$ is the bivariate normal distribution of $\varepsilon_{i t}^{1}$ and $\varepsilon_{i t}^{2}$. If we define the four regions of $\left(\varepsilon_{i t}^{1}, \varepsilon_{i t}^{2}\right)$ as $\mathrm{R}(1,1), \mathrm{R}(1,0), \mathrm{R}(0,1)$ and $\mathrm{R}(0,0)$ respectively, and the corresponding truncated distributions as $F_{2}\left(\varepsilon_{i t}^{1}, \varepsilon_{i t}^{2}\right) \mid \mathrm{R}(1,1)$ et cetera, then the likelihood function can also be written as

$$
\begin{aligned}
& \mathcal{L}=\prod_{i, t} f_{1}\left(T \dot{F P}_{l t}-\left(\gamma_{t}+\beta_{1}^{\prime} x_{i t}^{1}+\alpha_{12}+\beta_{2}^{\prime} x_{i t}^{2}+\varepsilon_{i t}^{1}+\varepsilon_{i t}^{2}\right) \mid R(1,1)\right) F_{2}\left(\varepsilon_{i t}^{1}, \varepsilon_{i t}^{2} \mid R(1,1)\right) \\
& \\
& \times f_{1}\left(T \dot{F} P_{l t}-\left(\gamma_{t}+\beta_{1}^{\prime} x_{i t}^{1}+\varepsilon_{i t}^{1}\right) \mid R(1,0)\right) F_{2}\left(\varepsilon_{i t}^{1}, \varepsilon_{i t}^{2} \mid R(1,0)\right) \\
& \times f_{1}\left(T \dot{F F} P_{l t}-\left(\gamma_{t}+\beta_{2}^{\prime} x_{i t}^{2}+\varepsilon_{i t}^{2}\right) \mid R(0,1)\right) F_{2}\left(\varepsilon_{i t}^{1}, \varepsilon_{i t}^{2} \mid R(0,1)\right) \\
& \times f_{1}\left(T \dot{F F} P_{l t}-\gamma_{t} \mid R(0,0)\right) F_{2}\left(\varepsilon_{i t}^{1}, \varepsilon_{i t}^{2} \mid R(0,0)\right)
\end{aligned}
$$

In practice the variance-covariance matrix must be imposed to be positive definite. This can be done by using a Cholesky factorization of $\Omega$. In the appendix we indicate the various steps taken to calculate the maximum simulated likelihood using the Geweke-Hajivassiliou- Keane (GHK) procedure (see Train, 2003; Cappellari and Jenkins, 2006).

We measure TFP growth using the index approach, that is, we assume constant returns to scale, equilibrium factor holdings and perfectly competitive markets, such that the output elasticities can be measured by the observed factor shares, which we allow to vary over time and to be industry-specific. We are interested in differences in the contributions to TFP growth for firms adopting different investment profiles: $(0,0),(1,0),(0,1)$ and $(1,1)$. These differences can be estimated by drawing values for $\varepsilon_{i t}^{1}$ and $\varepsilon_{i t}^{2}$ from their respective domains of definition and then averaging over the different draws. We are also interested in finding out whether those different investments reinforce each other. This indication of complementarity (or substitutability) is given by the sign of coefficient $\alpha_{12}$. 
The model we have just presented can be generalized to more than two strategies. In the remainder of the paper we shall work with three strategies : investment in ICT, R\&D, and organizational innovation. To determine the optimal investment profile, i.e. combination of strategies, each combination needs to be compared with seven other combinations. We shall estimate pairwise complementarities and returns from investing in ICT only, R\&D only, organizational innovation only, pairs of investments, all three of them or none at all.

\section{Data}

The data used in this exercise are sourced from the Business Register and different surveys at Statistics Netherlands, which are linked at the firm level. The sample includes firms in the manufacturing sector (NACE Rev. 210 to 33) as well as the services sector (NACE Rev. 2 50 to 93 ). ${ }^{4}$ Production data (value added, capital depreciation costs, and employment) are taken from the Production Statistics (PS). Capital services are proxied by depreciation costs (observed at the firm-level).Value added and depreciation cost are deflated using industrylevel price information from the Dutch National Accounts. Information on the age of a firm, and whether it is foreign-owned, is derived from the Business Register.

Information on R\&D and organizational innovation, as well as the export status is sourced from the Community Innovation Survey (CIS). Organizational innovations include the introduction of new business practices, knowledge management systems, methods of workplace organization (i.e. system of decision making), and management of external relations. The CIS provides information on whether a firm stated to have performed such an innovation or not in the three-year period ending in the year preceding the survey (for example, the CIS 2010 is carried out in 2011 and concerns the period 2008 to 2010). R\&D investment is the sum of internal and external $R \& D$ and, unlike organizational innovation, refers only to the last year of the survey.

Information on ICT investment comes from the investment survey, and concerns hardware only. ${ }^{5}$ We have decided to treat the three investment types in the same way, and therefore we work with binary data for ICT and R\&D, which is the only type of information we have for organizational innovation. In our analysis, a firm classifies as investing in ICT and R\&D when the investment is positive, but the investment should also have some substance. This is to improve the identification of any effects of investment on TFP, where really small investments can be expected not to make any difference, and we need to distinguish between those and more substantial investment efforts. By way of threshold, we therefore exploited industry-specific data on depreciation cost by type of investment. The investment dummies then

\footnotetext{
${ }^{4}$ The commercial R\&D sector, NACE Rev 2 code 72, is excluded from the analysis, as well as Oil and petroleum, NACE Rev 2 code 19.

${ }^{5}$ From 2012 onwards the Dutch Investment Survey includes information on investment in software. Including software would have substantially reduced the number of observations.
} 
equal 1 when the ratio of the firm's investment to its value added, exceeds the share of the depreciation cost for that capital good in value added in the firm's industry. Table A1 reports the annual average of these thresholds by industry. Thus, the investment dummies can be loosely interpreted as capturing whether a firm has expansionary investments or not, over and above the average industry replacement rate.

Our data span the period from 2008 to 2014. We assume that R\&D and ICT in period $t$ and ORG in period $t$-2 to $t$ affect TFP growth between year $t$ and year $t+1$. Because CIS only covers even years, the eventual estimation sample refers to 2008, 2010 and 2012, where TFP growth concerns growth from 2008 to 2009 et cetera. A sensitivity analysis where the timing of the ICT and R\&D investment dummies refers to $t$-2 rather than $t$, gave more or less similar results as those reported in the results section of this paper.

Table 1 gives the summary statistics by sector for the key variables used in the estimation, separately for manufacturing and services. Firms in both sectors are on average of a similar size, whereas manufacturing firms are slightly older than their counterparts in services. Moreover, manufacturing firms are more often foreign-owned, and are more likely to export. Overall, the share of exporting firms is relatively high, which is probably due to the fact that we observe mainly larger firms.

Table 1. Summary statistics for the (estimation sample, 2008-2012, even years)

\begin{tabular}{llrrrrrr} 
& & \multicolumn{2}{c}{ manufacturing } & \multicolumn{2}{c}{ services } & \multicolumn{2}{c}{ total } \\
& & mean & stdev & mean & stdev & mean & stdev \\
ICT investment & share of firms & 0.42 & 0.49 & 0.40 & 0.49 & 0.41 & 0.49 \\
R\&D investment & share of firms & 0.27 & 0.44 & 0.19 & 0.39 & 0.22 & 0.41 \\
organizational innovation* & share of firms & 0.45 & 0.50 & 0.35 & 0.48 & 0.39 & 0.49 \\
TFP growth** & \% & -0.05 & 0.31 & -0.04 & 0.29 & -0.04 & 0.30 \\
employment & Fte & 257.31 & 436.03 & 241.01 & 526.86 & 247.21 & 494.33 \\
age & Years & 24.31 & 15.18 & 20.13 & 15.05 & 21.72 & 15.24 \\
export status & share of firms & 0.82 & 0.39 & 0.56 & 0.50 & 0.66 & 0.47 \\
foreign owned & share of firms & 0.34 & 0.47 & 0.26 & 0.44 & 0.29 & 0.46
\end{tabular}

* organizational innovation refers to the period $t$-2 to $t$

** TFP growth refers to growth from $t$ to $t+1$

Average TFP growth is negative in both sectors, with a similar magnitude of respectively minus $5 \%$ in manufacturing, and minus $4 \%$ in services. The fact that our data period includes the financial crisis of 2008/2009 explains these substantial negative growth figures, where average (median) TFP growth was minus 10 (minus 5) percent in these years. In the other years, TFP growth is roughly around 0 . Table 2 also shows that for each investment profile there are firms reporting negative as well as positive growth, and that the third quartile of the TFP growth distribution is always positive. Interestingly, the distribution of TFP growth seems to roughly move to the right with the number of investments. That is, average and median TFP growth, as well as the first and third quartile of the distribution, are larger for those profiles where multiple investments are combined. This is an indication of complementarity 
between these investments, which will be tested more formally in our econometric model. Nevertheless, firms do not often combine these investments, witness the frequency distribution of the profiles (table 2). In manufacturing, about two-thirds of the observations concerns cases where a firm does not invest at all, or in a single strategy only. In services, this share is even higher, with about three-quarters of the sample.

Table 2. Combinations of investment strategies (estimation sample, 2008-2012, even years)

Manufacturing

\begin{tabular}{|c|c|c|c|c|c|c|}
\hline \multirow[b]{2}{*}{ profile } & \multirow[b]{2}{*}{$\mathrm{N}$} & \multirow[b]{2}{*}{$\%$} & \multicolumn{4}{|c|}{ TFP growth* } \\
\hline & & & mean & median & Q1 & Q3 \\
\hline 000 & 802 & 0.29 & -0.067 & -0.029 & -0.186 & 0.095 \\
\hline 001 & 430 & 0.15 & -0.062 & -0.014 & -0.170 & 0.094 \\
\hline 010 & 123 & 0.04 & -0.062 & -0.009 & -0.224 & 0.081 \\
\hline 011 & 266 & 0.09 & -0.023 & -0.014 & -0.146 & 0.097 \\
\hline 100 & 484 & 0.17 & -0.039 & -0.018 & -0.158 & 0.092 \\
\hline 101 & 335 & 0.12 & -0.054 & -0.039 & -0.192 & 0.106 \\
\hline 110 & 140 & 0.05 & -0.088 & -0.021 & -0.211 & 0.127 \\
\hline 111 & 227 & 0.08 & -0.008 & 0.018 & -0.124 & 0.128 \\
\hline & 2807 & & & & & \\
\hline
\end{tabular}

services

\begin{tabular}{|c|c|c|c|c|c|c|}
\hline \multirow[b]{2}{*}{ profile } & \multirow[b]{2}{*}{$\mathrm{N}$} & \multirow[b]{2}{*}{$\%$} & \multicolumn{4}{|c|}{ TFP growth* } \\
\hline & & & mean & median & Q1 & Q3 \\
\hline 000 & 1665 & 0.36 & -0.048 & -0.020 & -0.159 & 0.094 \\
\hline 001 & 659 & 0.14 & -0.059 & -0.018 & -0.156 & 0.077 \\
\hline 010 & 181 & 0.04 & -0.024 & 0.020 & -0.158 & 0.112 \\
\hline 011 & 259 & 0.06 & -0.041 & 0.001 & -0.149 & 0.097 \\
\hline 100 & 948 & 0.21 & -0.038 & -0.014 & -0.147 & 0.094 \\
\hline 101 & 450 & 0.10 & -0.030 & -0.006 & -0.130 & 0.105 \\
\hline 110 & 162 & 0.04 & -0.019 & -0.008 & -0.156 & 0.138 \\
\hline 111 & 252 & 0.06 & 0.001 & 0.006 & -0.126 & 0.128 \\
\hline & 4576 & & & & & \\
\hline
\end{tabular}

Q1 and Q3 are the first and third quartile of the distribution. Combinations of ICT, R\&D, and organizational innovation, where $0=$ no investment and $1=$ positive (net) investment. Organizational innovation refers to the period $t-2$ to $t$.

* TFP growth refers to growth from $t$ to $t+1$ 
Table 3 reports the summary statistics of the variables that are input to the TFP growth calculation. Using a Laspeyres-index, TFP-growth was calculated as the ratio of the volume changes in value added and the total of inputs, where the capital and labour changes have been weighted by their lagged factor shares at the industry-level. This approach takes into differences in the nature of the production process between industries. Clearly, the average TFP growth differs across industries, with the pharmaceutical industry being a clear outlier.

Table 3. Summary statistics for the production variables (estimation sample, 2008-2012, even years)

\begin{tabular}{|c|c|c|c|c|c|c|}
\hline & \multicolumn{2}{|c|}{$\begin{array}{c}\text { Industry variables } \\
\text { Averages across years }\end{array}$} & \multicolumn{4}{|c|}{$\begin{array}{l}\text { Firm variables } \\
\text { across industry }\end{array}$} \\
\hline & $\begin{array}{c}\text { capital } \\
\text { share }\end{array}$ & $\begin{array}{l}\text { labour } \\
\text { share }\end{array}$ & $\begin{array}{l}\text { value } \\
\text { added }\end{array}$ & $\begin{array}{l}\text { employ- } \\
\text { ment }\end{array}$ & $\begin{array}{l}\text { capital } \\
\text { services }\end{array}$ & $\begin{array}{c}\text { TFP } \\
\text { growth }\end{array}$ \\
\hline \multicolumn{7}{|l|}{ Manufacturing } \\
\hline 10-12 Food and beverages & 0.35 & 0.65 & 22468 & 265 & 3400 & -0.050 \\
\hline 13-15 Textile-, leatherproducts & 0.27 & 0.73 & 9898 & 115 & 741 & 0.017 \\
\hline 16-18 Wood and paper, printing & 0.32 & 0.68 & 13527 & 162 & 2092 & 0.012 \\
\hline 20 Chemicals & 0.50 & 0.50 & 42740 & 195 & 6386 & -0.092 \\
\hline 21 Pharmaceuticals & 0.52 & 0.48 & 69118 & 433 & 5176 & 0.283 \\
\hline 22-23 Plastics, construction products & 0.28 & 0.72 & 12611 & 192 & 1943 & 0.037 \\
\hline 24-25 Basic metals and -products & 0.24 & 0.76 & 11222 & 144 & 1113 & -0.002 \\
\hline 26 Electronic products & 0.40 & 0.60 & 23626 & 239 & 1497 & 0.137 \\
\hline 27 Electric equipment & 0.50 & 0.50 & 31100 & 410 & 4059 & -0.047 \\
\hline 28 Machinery n.e.c. & 0.28 & 0.72 & 22889 & 233 & 2486 & -0.025 \\
\hline 29-30 Transport equipment & 0.33 & 0.67 & 37808 & 398 & 4730 & 0.039 \\
\hline 31-33 Other manufacturing, repair & 0.15 & 0.85 & 19807 & 482 & 1069 & -0.005 \\
\hline \multicolumn{7}{|l|}{ Services } \\
\hline 58-60 Publishing, movie, radio and TV & 0.16 & 0.84 & 22784 & 247 & 4405 & -0.040 \\
\hline 61 Telecommunications & 0.62 & 0.38 & 57741 & 275 & 25460 & 0.073 \\
\hline 62-63 IT- and information services & 0.12 & 0.88 & 15288 & 170 & 1497 & 0.036 \\
\hline 69-71 Management, tech. consultancy & 0.10 & 0.90 & 20151 & 253 & 1100 & -0.032 \\
\hline 73-75 Advertising, design and other & 0.11 & 0.88 & 8622 & 126 & 627 & 0.023 \\
\hline G Wholesale and retail trade & 0.20 & 0.80 & 15598 & 218 & 1460 & -0.023 \\
\hline H Transportation and storage & 0.32 & 0.68 & 25648 & 309 & 3430 & -0.006 \\
\hline I Accommodation and food serving & 0.17 & 0.83 & 10424 & 213 & 1894 & -0.030 \\
\hline
\end{tabular}

Value added and depreciation cost in prices of 2008. Employment in full-time equivalents.

\section{Results}

In this section, we report the estimation results of the integrated model with three types of investment, the returns for each investment profile, and the individual returns of each investment, both on average and as a contribution to the return of each investment profile. Antici- 
pating that the patterns differ across industries, we present the estimation results separately for manufacturing and services.

\subsection{Complementarities}

In table 4 we report the results for the integrated model with simultaneous discrete-choice investment equations for ICT, R\&D and organizational innovation, mutual dependence among the three types of investment and controlling for firm size, export status, age, and foreign ownership, and for four industry sub-sectors in services. ${ }^{6}$ Firm size can be seen to be positively associated with investing in our sample, except for investments in ICT for firms in manfacturing and in R\&D for firms in services. Exporting firms are more frequently observed to invest in R\&D, less frequently in ICT and not particularly different from non-exporting in terms of organizational innovation. ${ }^{7}$ Age is not found to be significant in any of the three equations. Foreign ownership is positively correlated to organizational innovation, and negatively, whenever significant, to ICT and R\&D investments. As already mentioned before, TFP growth was negative just after the crisis of 2008, but then recovered in the following years. The correlations between the error terms are significant, attesting to the existence of unobservables that are correlated in the adoption and the productivity equations, which justifies our estimation approach.

The three types of investment turn out to be complementary in the sense that they reinforce each other in increasing TFP growth and hence that the probability of investing in one increases the probability of investing in the other one. It is only for ICT and organizational innovation that we do not obtain a positive and significant interaction term. In the logic of our model, two investments are carried out simultaneously if they yield a larger contribution to TFP growth than if they are carried out separately or not at all. Three investments are carried out simultaneously if together they increase TFP growth by more than any pair of investments, individual investment or no investment at all. The coefficient for the combination of ICT and organizational innovation is significantly smaller than the other $\alpha$ coeffients, in both sectors. This is surprising because given the existing evidence in the literature one would expect this relation to be relatively strong. A possible explanation for this finding is that we consider investment in hardware only, while the complementarity with organizational innovation could lie more in the use of software and specific types of telecommunication equipment.

By contrast, the R\&D and organizational innovation combination is significant and has the highest coefficient in both sectors. This suggests that firms that invest in R\&D believe they will benefit from a simultaneous organizational change. Such a complementarity could be related to the introduction of knowledge management systems, or the management of external

\footnotetext{
${ }^{6}$ To assess more properly the magnitude of the coefficients we would need to calculate the marginal effects, which can be done by the delta method. We plan to do so in upcoming revisions to this paper. Doing so will, however, not alter any qualitative conclusion about patterns of significance.

${ }^{7}$ Clearly, the causality can run both ways here. Including export status is meant to control for the degree of international activities here.
} 
relations (such as information flows or coordination of collaborative innovation efforts), which are seen as an organizational innovation, and which clearly could improve the effectiveness of R\&D. To our knowledge there is not much evidence in the literature on this relation, and our finding suggests that it could be explored in further detail.

Finally, investing in ICT and R\&D are found to be complementary decisions, in the sense that investing in one increases the productivity of investing in the other one. This lends supports to the idea that ICT is a general purpose technology that facilitates innovation and increases the output and productivity of R\&D (Jovanovic and Rousseau, 2005). Vice versa, investing in $R \& D$ increases the returns to ICT by generating knowledge that can be shared and diffused through new technology.

In sum, our results suggest that firms consider investment in ICT, R\&D, and organizational innovation simultaneously, and that they believe that simultaneous investment can be beneficial. In the next section we shall examine the returns of investing in certain profiles and the expected returns from individual investments.

Table 4. Estimation results of the investment plus productivity equations

(based on Maximum Simulated Likelihood)

\begin{tabular}{|c|c|c|c|c|c|c|c|c|c|}
\hline & \multicolumn{4}{|c|}{ Manufacturing $(\mathrm{N}=2,807)$} & \multicolumn{4}{|c|}{ Services $(\mathrm{N}=4,576)$} \\
\hline & & coef & & se & p-value & coef & & se & p-value \\
\hline \multirow[t]{4}{*}{ ICT } & log employment & -0.079 & F* & 0.017 & 0.000 & 0.060 & F*** & 0.013 & 0.000 \\
\hline & export status & -0.121 & ${ }^{* * *}$ & 0.045 & 0.008 & -0.014 & & 0.029 & 0.637 \\
\hline & log age & 0.012 & & 0.016 & 0.452 & 0.000 & & 0.012 & 0.996 \\
\hline & oreign ownership & -0.086 & ** & 0.038 & 0.024 & -0.091 & $* *$ & 0.033 & 0.006 \\
\hline \multirow[t]{4}{*}{$R \& D$} & log employment & -0.005 & & 0.024 & 0.838 & -0.068 & *** & 0.016 & 0.000 \\
\hline & export status & 0.524 & *** & 0.074 & 0.000 & 0.289 & *** & 0.041 & 0.000 \\
\hline & log age & -0.004 & & 0.027 & 0.869 & -0.002 & & 0.019 & 0.930 \\
\hline & oreign ownership & 0.019 & & 0.050 & 0.704 & -0.104 & $* *$ & 0.044 & 0.019 \\
\hline \multirow[t]{4}{*}{ ORG } & log employment & 0.147 & *** & 0.021 & 0.000 & 0.108 & *** & 0.015 & 0.000 \\
\hline & export status & -0.004 & & 0.054 & 0.942 & -0.044 & & 0.034 & 0.195 \\
\hline & log age & 0.011 & & 0.021 & 0.605 & 0.008 & & 0.015 & 0.574 \\
\hline & oreign ownership & 0.116 & ${ }^{* *}$ & 0.044 & 0.008 & 0.070 & ${ }^{*}$ & 0.038 & 0.064 \\
\hline \multirow[t]{3}{*}{ TFP growth } & Year 2010 & 0.164 & ${ }^{* * *}$ & 0.018 & 0.000 & 0.101 & $* * *$ & 0.014 & 0.000 \\
\hline & Year 2012 & 0.118 & *** & 0.023 & 0.000 & 0.071 & $* * *$ & 0.017 & 0.000 \\
\hline & intercept & -0.653 & ${ }^{* * *}$ & 0.021 & 0.000 & -0.498 & *** & 0.014 & 0.000 \\
\hline \multirow[t]{3}{*}{ complementarities } & ICT - R\&D & 0.251 & ${ }^{* * *}$ & 0.027 & 0.000 & 0.175 & *** & 0.025 & 0.000 \\
\hline & ICT-ORG & -0.044 & & 0.038 & 0.245 & 0.046 & $* *$ & 0.019 & 0.018 \\
\hline & R\&D-ORG & 1.279 & ${ }^{* * *}$ & 0.072 & 0.000 & 1.129 & *** & 0.020 & 0.000 \\
\hline \multirow[t]{8}{*}{ Correlations } & $\rho 12$ & -0.229 & ${ }^{* * *}$ & 0.034 & 0.000 & 0.173 & *** & 0.024 & 0.000 \\
\hline & $\rho 13$ & 0.166 & ${ }^{* * *}$ & 0.044 & 0.000 & 0.045 & $* *$ & 0.019 & 0.018 \\
\hline & $\rho 14$ & -0.742 & ${ }^{* * *}$ & 0.021 & 0.000 & 0.811 & *** & 0.007 & 0.000 \\
\hline & $\rho 23$ & -0.771 & ${ }^{* * *}$ & 0.036 & 0.000 & -0.061 & $*$ & 0.035 & 0.079 \\
\hline & $\rho 24$ & 0.254 & *** & 0.049 & 0.000 & 0.011 & & 0.032 & 0.733 \\
\hline & $\rho 34$ & -0.517 & ${ }^{* * *}$ & 0.028 & 0.000 & -0.695 & *** & 0.015 & 0.000 \\
\hline & $\sigma 4$ & 0.553 & *** & 0.015 & 0.000 & 0.503 & $* * *$ & 0.010 & 0.000 \\
\hline & Log-likelihood & -6561.124 & & & & -9912.214 & & & \\
\hline
\end{tabular}

Significance at $10 \%(*) ; 5 \%(* *) ; 1 \%(* * *)$. Intercepts in the probit equations and sector dummies for services are not reported. $\rho 12$ is the correlation between the error terms of equations 1 and 2 . The equations are numbered as follows: $1=\mathrm{ICT}, 2=\mathrm{R} \& \mathrm{D}, 3=\mathrm{ORG}, 4=\mathrm{TFP}$ growth. 


\subsection{Returns on investments}

In our model, the expected return from a given investment profile is the same as the ex-post return in terms of TFP growth. If a certain profile is chosen, it is because its realized return is higher than the return on any other investment profile. In table 5 we present the average and the standard deviation of the returns earned on the seven investment profiles in manufacturing and in services. ${ }^{8}$ In the example of two strategies given above the return to adopting investment profile $(1,1)$ would be given by

$$
\left(\left(\beta_{1}^{\prime} x_{i t}^{1}+\alpha_{12}+\beta_{2}^{\prime} x_{i t}^{2}+\varepsilon_{i t}^{1}+\varepsilon_{i t}^{2}\right) \mid R(1,1)\right) F_{2}\left(\varepsilon_{i t}^{1}, \varepsilon_{i t}^{2} \mid R(1,1)\right)
$$

where $\mathrm{R}(1,1)$ are all values of $\varepsilon_{i t}^{1}$ and $\varepsilon_{i t}^{2}$ defined by restrictions (5.1) and (5.2).

These returns are to be understood as above-normal rates of return, since R\&D and ICT are not subtracted from the traditional inputs (labor and capital) in the calculation of TFP growth. These returns are random in the sense that they depend on unobservables that lie in a truncated part of their distribution, which is determined by the observed investment profile, and are to be understood as the returns conditional on having chosen that investment profile times the probability of chosing that investment profile. They are calculated via simulation using the same draws as in the estimation procedure. According to our model, for each observation the alternative investment profiles yield a return lower than the observed profile. In the case of pairs or triplets of investment, the joint returns are subdivided in the table, into the returns earned on the individual investments.

The highest return is earned by firms that invest at the same time in ICT and organizational innovation, followed by firms that invest in ICT only. Note that we are not comparing the same firms under alternative investment profiles. In most cases, the alternative (counterfactual) returns (not shown) are negative, although they only need to be lower than the returns earned on the chosen investment profile. So, it could be that the differences in return are due to different characteristics of the firms, like size, age or export status. The returns for firms that invest in all three strategies is, for instance, smaller than the returns for firms that invest only in ORG, only in ICT or in both ORG and ICT. According to the complementarities, we would have expected the highest returns for firms that invest in all strategies. But, the thing is that we are not comparing the same firms under different scenarios. It is remarkable that the ranking of the returns per investment profile and even the magnitudes of those returns are very similar for firms in manufacturing and in services.

Now, we turn to table 6, where we present the expected returns to each individual investment. These returns are calculated as follows. The expected rate of return on $R \& D$, for instance, is the return a firm gets if it belongs to the set of investment profiles $(0,1,0),(1,1,0),(0,1,1)$ and $(1,1,1)$ multipled by the respective probabilities of choosing each of those profiles.. Since a firm can be in eight zones of the space spanned by $\left(\varepsilon_{i t}^{1}, \varepsilon_{i t}^{2}, \varepsilon_{i t}^{3}\right)$, and since it makes no return

\footnotetext{
${ }^{8}$ Note that the returns in the $(0,0,0)$ case, where no investment takes place, is 0 by definition and is not reported.
} 
on a particular strategy if it does not invest in that strategy, this return is truly the expected return made on a certain type of investment. It is interesting to notice that the returns are again very similar in manufacturing and in services. Investing in ICT yields on average an expected rate of return close to $10 \%$, which can go as high as $33.5 \%$ in manufacturing and $23.1 \%$ in services. R\&D earns on average only $1.8 \%$ in manufacturing and $1.4 \%$ in services, with at most $8.8 \%$ in manufacturing and $4.7 \%$ in services. This is definitely lower than the average rates of return on R\&D reported in Hall et al. (2010) and those reported for the Netherlands by Bartelsman, van Leeuwen, Nieuwenhuijsen and Zeelenberg (1989). The expected rate of return on organizational innovation lies in between the rate on R\&D and ICT with an average of $7.3 \%$ in manufacturing and $5.9 \%$ in services, which can exceed $20 \%$.

Table 5. Returns to investment profiles and contribution of individual investments.

\begin{tabular}{|c|c|c|c|c|c|c|c|c|c|c|c|}
\hline \multirow[b]{2}{*}{ profile } & & \multicolumn{5}{|c|}{ Manufacturing } & \multicolumn{5}{|c|}{ Services } \\
\hline & & obs & mean & st. dev & $\min$ & $\max$ & obs & mean & st. dev & $\min$ & $\max$ \\
\hline \multirow[t]{2}{*}{$(0,0,1)$} & ORG only & 430 & 0.107 & 0.035 & 0.033 & 0.238 & 659 & 0.090 & 0.025 & 0.039 & 0.205 \\
\hline & ORG & & 0.107 & 0.035 & 0.033 & 0.238 & 659 & 0.090 & 0.025 & 0.039 & 0.205 \\
\hline \multirow[t]{2}{*}{$(0,1,0)$} & $R \& D$ only & 123 & 0.034 & 0.009 & 0.010 & 0.053 & 181 & 0.024 & 0.009 & 0.006 & 0.047 \\
\hline & R\&D & & 0.034 & 0.009 & 0.010 & 0.053 & 181 & 0.024 & 0.009 & 0.006 & 0.047 \\
\hline \multirow[t]{3}{*}{$(0,1,1)$} & $R \& D$ and $O R G$ & 266 & 0.057 & 0.031 & 0.003 & 0.195 & 259 & 0.033 & 0.011 & 0.010 & 0.061 \\
\hline & R\&D & & 0.021 & 0.012 & -0.001 & 0.088 & 259 & 0.012 & 0.006 & -0.001 & 0.030 \\
\hline & ORG & & 0.036 & 0.025 & 0.002 & 0.159 & 259 & 0.021 & 0.008 & 0.007 & 0.041 \\
\hline \multirow[t]{2}{*}{$(1,0,0)$} & ICT only & 484 & 0.145 & 0.052 & 0.035 & 0.335 & 948 & 0.143 & 0.027 & 0.071 & 0.231 \\
\hline & ICT & & 0.145 & 0.052 & 0.035 & 0.335 & 948 & 0.143 & 0.027 & 0.071 & 0.231 \\
\hline \multirow[t]{3}{*}{$(1,0,1)$} & ICT and $O R G$ & 335 & 0.164 & 0.027 & 0.105 & 0.266 & 450 & 0.121 & 0.036 & 0.053 & 0.298 \\
\hline & ICT & & 0.083 & 0.016 & 0.052 & 0.140 & 450 & 0.062 & 0.019 & 0.027 & 0.159 \\
\hline & ORG & & 0.081 & 0.016 & 0.039 & 0.129 & 450 & 0.058 & 0.019 & 0.024 & 0.146 \\
\hline \multirow[t]{3}{*}{$(1,1,0)$} & $I C T$ and $R \& D$ & 140 & 0.044 & 0.014 & 0.012 & 0.075 & 162 & 0.037 & 0.013 & 0.012 & 0.082 \\
\hline & ICT & & 0.025 & 0.008 & 0.006 & 0.044 & 162 & 0.021 & 0.007 & 0.007 & 0.043 \\
\hline & $\mathrm{R} \& \mathrm{D}$ & & 0.020 & 0.007 & 0.004 & 0.039 & 162 & 0.016 & 0.006 & 0.005 & 0.038 \\
\hline \multirow[t]{4}{*}{$(1,1,1)$} & all investments & 227 & 0.102 & 0.023 & 0.017 & 0.174 & 252 & 0.064 & 0.024 & 0.023 & 0.165 \\
\hline & ICT & & 0.059 & 0.011 & 0.013 & 0.082 & 252 & 0.036 & 0.013 & 0.014 & 0.091 \\
\hline & $\mathrm{R} \& \mathrm{D}$ & & 0.004 & 0.007 & -0.019 & 0.023 & 252 & 0.008 & 0.006 & -0.003 & 0.028 \\
\hline & ORG & & 0.039 & 0.014 & 0.005 & 0.091 & 252 & 0.020 & 0.009 & 0.005 & 0.062 \\
\hline
\end{tabular}


Table 6. Expected returns to individual investments.

\begin{tabular}{lrrrrr}
\multicolumn{5}{c}{ Manufacturing } & Max \\
ICT & Obs & Mean & Std. Dev. & Min & 0.335 \\
R\&D & 1,186 & 0.097 & 0.055 & 0.006 & 0.088 \\
ORG & 756 & 0.018 & 0.014 & -0.019 & 0.238 \\
& 1,258 & 0.073 & 0.040 & 0.002 & Max \\
& & Services & & & 0.231 \\
ICT & Obs & Mean & Std. Dev. & Min & 0.047 \\
R\&D & 1,812 & 0.097 & 0.054 & 0.007 & 0.205 \\
ORG & 854 & 0.014 & 0.009 & -0.003 &
\end{tabular}

\section{Conclusions and further research}

This paper has investigated the relation between investments in ICT, R\&D and organizational innovation, and the effects of different investment profiles on TFP growth at the firm-level. We find that the investment decisions are complementary, in the sense that investing in one direction increases the probability of investing in another because joint investments lead to higher TFP growth than individual investments. We find a strong complementarity between $\mathrm{R} \& \mathrm{D}$ and organizational innovation, which could be related to new ways of managing knowledge systems and external relations. To our knowledge this relation has not been explored intensively in the literature. The fact that the magnitude of the complementarity between ICT and organizational innovation is lower than the other complementarities also merits some further investigation, in particular considering software investments in addition to hardware. There is clear evidence that ICT and R\&D complement each other. This means that R\&D policies stimulate investments in ICT, and conversely policies designed to stimulate ICT also increase the demand for R\&D. ICT earns on average an expected rate of return of $9.7 \%$, followed by $6 \%$ to $7 \%$ on organizational innovation and a modest $1.4 \%$ to $1.8 \%$ on R\&D.

Our plans are to extend this paper further in a number of directions. Firstly, we want to exploit different types of organizational innovation that are available in our data (business practices, knowledge systems, and external relations), as they could relate differently to ICT and R\&D. Secondly, as mentioned above, it will be good to consider software investment next to hardware investment even though we only have data from 2012 for this type of asset. Thirdly, we could estimate the elasticities of labor and capital together with the returns to ICT, R\&D and organizational innovation. A fourth extension would be to use the intensities of R\&D and ICT in the productivity growth equation instead of, or in addition to, just the binary information. 


\section{References}

Aboal, D. and E. Tacsir (2018), "Innovation and productivity in services and manufacturing: the role of ICT”, Industrial and Corporate Change, 27(2), 221-241.

Athey, S. and S. Stern (1998), “An Empirical Framework for Testing Theories About Complimentarity in Organizational Design”, NBER working paper 6600.

Bartelsman, E., G. van Leeuwen, H. Nieuwenhuijsen and K. Zeelenberg (1996), "R\&D and productivity growth: evidence from firm-level data in the Netherlands", Netherlands Official Statistics, 11 (Autumn), 52-69.

Bartelsman, E., G. van Leeuwen and M. Polder (2017), "CDM using a cross country micro moments database”, Economics of Innovation and New Technology, 26(1/2), 168-182.

Biagi, F. (2013), “ICT and Productivity: A Review of the Literature:”, JRC Technical Reports, Institute for Prospective Technological Studies, Digital Economy working paper 2013/09.

Black, S. E., and L. M. Lynch (2001), "How to compete: the impact of workplace practices and information technology on productivity." The Review of Economics and Statistics, 83(3): 434-445.

Bresnahan, T. F., E. Brynjolfsson and L. M. Hitt (2002), "Information technology, workplace organization, and the demand for skilled labor: firm-level evidence." Quarterly Journal of Economics, 117(1): 339-376.

Brynjolfsson, E. and L. M. Hitt (2000), “Beyond Computation: Information Technology, Organizational Transformation and Business Performance.” Journal of Economic Perspectives, 14(4): 23-48.

Brynjolfsson, E. and A. MacAfee (2014), The Second Machine Age, MIT Press.

Brynjolfsson, E. and Saunders, A. (2010) Wired for Innovation - How Information Technology Is Reshaping the Economy. Cambridge, MA: The MIT Press.

Cappellari, L., and S. P. Jenkins (2006) "Calculation of Multivariate Normal Probabilities by Simulation, with Applications toMaximum Simulated Likelihood Estimation.” The Stata Journal 6 (2): 156-189.

Caroli E. and J. Van Reenen (2001), “Organization, Skills and Technology: Evidence from a Panel of British and French Establishments”, Quarterly Journal of Economics, 116(4), 14491492.

Cerquera, D. and G.J. Klein (2008), "Endogenous firm heterogeneity, ICT and R\&D incentives”, ZEW discussion paper No. 08-126. 
Chen, W., T. Niebel and M. Saam (2014) "Are intangibles more productive in ICT-intensive industries? Evidence from EU countries”, ZEW discussion paper 14-070.

Corrado, C. A., C. R. Hulten and D. E. Sichel (2009), "Intangible capital and U.S. economic growth”, Review of Income and Wealth, 5(3), 661-85.

Corrado, C., J. Haskel, C. Jona-Lasinio and M. Iommi (2013), “Innovation and intangible investment in Europe, Japan, and the United States”, Oxford Review of Economic Policy, 29, 261-286.

Corrado, C., J. Haskel and C. Jona-Lasinio (2017), “Knowledge Spillovers, ICT and Productivity Growth”, Oxford Bulletin of Economics and Statistics, doi: 10.1111/obes.12171.

Crépon, B., E. Duguet and J. Mairesse (1998), "Research, innovation and productivity : an econometric analysis at the firm level." Economics of Innovation and New Technology, 7: 115-158.

Crespi, G., C. Criscuolo, and J. Haskel (2007), "Information technology, organizational change and productivity growth: evidence from UK firms.” CEP Discussion Paper no. 783.

Doraszelski, U. and J. Jaumandreu (2013), "R\&D and productivity: Estimating endogenous productivity”, Review of Economic Studies, 80(4), 1338-1383.

Draca, M., R. Sadun and J. van Reenen (2007): Productivity and ICTs: A review of the evidence, Chapter 5 in Mansell, R., C. Avgerou, D. Quah and R. Silverstone (eds.): The Oxford Handbook of Information and Communication Technologies, Oxford University Press.

Engelstätter, B. (2012), "It is not all about performance gains - enterprise software and innovations”, Economics of Innovation and New Technology, 21(3):223-245.

Eurostat (2008), "Information Society: ICT impact assessment by linking data from different sources (Final Report).” Luxembourg: Eurostat.

Forman, C. C., and van Zeebroeck, N. (2012), "From wires to partners: How the Internet has fostered R\&D collaborations within firms”, Management Science, 58(8), 1549-1568.

Gordon, R. (2016), The Rise and Fall of American Growth: The U.S. Standard of Living since the Civil War, Princeton University Press.

Griliches, Z. (1979), "Issues in assessing the contribution of research and development to productivity growth”, Bell Journal of Economics, 10(1), 92-116.

Hall, B.H. , F. Lotti and J. Mairesse (2013), "Evidence on the impact of R\&D and ICT investments on innovation and productivity in Italian firms, Economics of Innovation and New Technology, 22(3), 300-328. 
Hall, B., J. Mairesse and P. Mohnen (2010), “Measuring the returns to R\&D”, in the Handbook of the Economics of Innovation, B. H. Hall and N. Rosenberg (editors), Elsevier, Amsterdam, 1034-1082.

Hall, B. (2005), "Measuring the returns to R\&D: The depreciation problem", Annales d'Economie et de Statistique 79/80, NBER working paper No. 13473 (September 2007).

Hall, B., Lotti, F. and J. Mairesse (2012), "Evidence on the impact of R\&D and ICT investment on innovation and productivity in Italian firms”, NBER working paper 18053.

Jorgenson, D. W., M. S. Ho, and K. J. Stiroh (2008), “A Retrospective Look at the U.S. Productivity Growth Resurgence.” Journal of Economic Perspectives, 22(1): 3-24.

Jovanovic, B. and P. L. Rousseau (2005), "General Purpose Technologies," in: P. Aghion and S. Durlauf (eds.), Handbook of Economic Growth, vol. 1, chap. 18, 1181-1224, Elsevier, Amsterdam.

Kleis, L., P. Chwelos, R.V. Ramirez and I. Cockburn (2012), "Information technology and intangible output: The impact of IT investment on innovation productivity", Information Systems Research, 23(1), 42-59.

Kretschmer, T., E. Miravete, and J. Pernías (2012), “Competitive Pressure and the Adoption of complementary innovations”, American Economic Review, 102(4), 1540-1570.

Leeuwen, G. van, and S. Farooqui (2008), “ICT, innovation and productivity.” In Eurostat "Information society: ICT impact assessment by linking data from different sources”, 222239.

Leeuwen, G. van and P. Mohnen (2017), "Revisiting the Porter hypothesis: An empirical analysis of green innovation in the Netherlands”, Economics of Innovation and New Technology, 26(1/2), 63-77.

Lewbel, A. (2007), “Coherency and completeness of structural models containing a dummy endogenous variable”, International Economic Review, 48(4), 1379-1392.

Lipsey, R., K. I. Carlaw and C. T. Bekhar (2005), Economic Transformations: General Purpose Technologies and Long Term Economic Growth. Oxford University Press, Oxford.

Mairesse, J. and P. Mohnen (2010), “Using innovation surveys for econometric analysis”, in the Handbook of the Economics of Innovation, B. H. Hall and N. Rosenberg (editors), Elsevier, Amsterdam, 1130-1155.

Martínez-Ros, E. and J. Labeaga (2009), "Product and process innovation: persistence and complementarities”, European Management Review, 6, 64-75.

Milgrom, P. and J. Roberts (1990), "The economics of modern manufacturing, technology, strategy and organizations.” American Economic Review, 80: 511-528. 
Miravete, E. and J. Pernías (2006), "Innovation complementarity and scale of production”, Journal of Industrial Economics, 54, 1-29.

Pieri, F., M Vecchi and F Venturini (2017), "Modelling the joint impact of R\&D and ICT on productivity: a frontier analysis approach”, working paper, Universita'degli Studi di Trento.

Polder, M. (2015), “Determinants of economic growth and productivity”, in: ICT and Economic Growth, CBS, Statistics Netherlands.

Polder, M., G. van Leeuwen, P. Mohnen and W. Raymond (2009), "Productivity effects of innovation modes”, Statistics Netherlands, working paper 09033.

Polder, M., G. van Leeuwen, P. Mohnen and W. Raymond (2010), "Product, process and organizational innovation: drivers, complementarity and productivity effects”, UNU-MERIT working paper 2010-035.

Riley, R. and P. Vahter (2013), "Innovation and productivity in services: The role of organizational capital and IT”, mimeo.

Rybalka (2015), “The innovative input mix. Assessing the importance of ICt and R\&D investments for firm performance in manufacturing and services”, discussion paper 801, Statistics Norway.

Spiezia, V. (2011), “Are ICT users more innovative?: An analysis of ICT-enabled innovation in OECD firms”, OECD Journal: Economic Studies, Vol. 2011/1.

Stiroh, K.J. (2010), "Reassessing the impact of information technology in the production function: A meta analysis and sensitivity tests”, in J. Mairesse and M. Trajtenberg, Contributions in Memory of Zvi Griliches. NBER books.

Syverson, C. (2010), “What determines productivity?”, Journal of Economic Literature, 49:2, 326-365.

Train, K. (2003), Discrete Choice Methods with Simulations. Cambridge (UK): Cambridge University Press.

Van Reenen J., N. Bloom, M. Draca, T. Kretschmer, R. Sadun, H. Overman and M. Schankerman (2010), “The Economic Impact of ICT”, Final Report for the European Commission. 
Appendix: Calculation of the maximum simulated likelihood

This part is based on Train (2003) and Capellari and Jenkins (2006). For simplicity we take the case of two strategies and one performance equation. The example can easily be generalized to 3 strategies and one performance equation. We start by using a Cholesky factorization of $\Omega$ :

$$
\left[\begin{array}{c}
\varepsilon_{i t}^{1} \\
\varepsilon_{i t}^{2} \\
\varepsilon_{i t}^{3}
\end{array}\right]=C\left[\begin{array}{l}
\eta_{i t}^{1} \\
\eta_{i t}^{2} \\
\eta_{i t}^{3}
\end{array}\right]=\left[\begin{array}{ccc}
c_{11} & 0 & 0 \\
c_{21} & c_{22} & 0 \\
c_{31} & c_{32} & c_{33}
\end{array}\right]\left[\begin{array}{l}
\eta_{i t}^{1} \\
\eta_{i t}^{2} \\
\eta_{i t}^{3}
\end{array}\right]
$$

with

$\Omega=C * C^{\prime}=\left[\begin{array}{ccc}1 & \rho_{21} & \rho_{31} \sigma_{3} \\ \rho_{21} & 1 & \rho_{32} \sigma_{3} \\ \rho_{31} \sigma_{3} & \rho_{32} \sigma_{3} & \sigma_{3}^{2}\end{array}\right]$ and each $\eta_{i t}^{j}(\mathrm{j}=1,2,3)$ follows a standard normal distribution.We set the variances of $\varepsilon_{i t}^{1}$ and $\varepsilon_{i t}^{2}$ equal to 1 for reasons of identification. In order to have this $\Omega$ matrix, we elements of $C$ are as follows: $c_{11}=1, c_{21}=\rho_{21}, c_{31}=\rho_{31} \sigma_{3}$, $c_{22}=\sqrt{\left(1-c_{21}{ }^{2}\right)}, c_{32}=\left(\rho_{32} \sigma_{3}-c_{31} * c_{21}\right) / c_{22}, c_{33}=\sqrt{\left(\sigma_{3}^{2}-c_{31}{ }^{2}-c_{32}{ }^{2}\right.}$. The $\rho_{i j}$ coefficients are imposed to stay between -1 and 1 by using the following reparameterization: $\rho_{i j}=\frac{\exp \left(2 \widetilde{\rho_{l J}}\right)-1}{\exp \left(2 \widetilde{\rho_{l J}}\right)+1}$

We can rewrite $\left[\begin{array}{c}\varepsilon_{i t}^{1} \\ \varepsilon_{i t}^{2} \\ \varepsilon_{i t}^{3}\end{array}\right]=\left[\begin{array}{c}c_{11} \eta_{i t}^{1} \\ c_{21} \eta_{i t}^{1}+c_{22} \eta_{i t}^{2} \\ c_{31} \eta_{i t}^{1}+c_{32} \eta_{i t}^{2}+c_{33} \eta_{i t}^{3}\end{array}\right]$

Inequalities (5.1), (7.1), (9.1) and (11.1) can be rewritten as:

$\eta_{i t}^{1}>-\left(\beta_{1}^{\prime} x_{i t}^{1}+\alpha_{12}\right)$

$\eta_{i t}^{1}>-\left(\beta_{1}^{\prime} x_{i t}^{1}\right)$

$\eta_{i t}^{1}<-\left(\beta_{1}^{\prime} x_{i t}^{1}+\alpha_{12}\right)$

$\eta_{i t}^{1}<-\beta_{1}^{\prime} x_{i t}^{1}$

The first step of the maximum simulated likelihood algorithm consists in drawing for each alternative a value from the corresponding truncated standard normal distribution of $\eta_{i t}^{1}$ using initial values of the parameters. Let us denote this value as $d_{i t}^{1}$.

Inequalities (5.2), (7.2), (9.2) and (11.2) can be rewritten as: 


$$
\begin{aligned}
& \eta_{i t}^{2}>\max \left(-\left(a_{2 i t}+\alpha_{12}\right) / c_{22},-\left(a_{1 i t}+a_{2 i t}+\alpha_{12}\right) / c_{22}\right) \\
& \eta_{i t}^{2}<\min \left(-\left(a_{2 i t}+\alpha_{12}\right) / c_{22},\left(a_{1 i t}-a_{2 i t}\right) / c_{22}\right) \\
& \eta_{i t}^{2}>\max \left(-a_{2 i t} / c_{22},\left(a_{1 i t}-a_{2 i t}\right) / c_{22}\right) \\
& \eta_{i t}^{2}<\min \left(-a_{2 i t} / c_{22},-\left(a_{1 i t}+a_{2 i t}+\alpha_{12}\right) / c_{22}\right)
\end{aligned}
$$

where $a_{1 i t}=\beta_{1}^{\prime} x_{i t}^{1}+d_{i t}^{1}, a_{2 i t}=\beta_{2}^{\prime} x_{i t}^{2}+c_{21} d_{i t}^{1}$.

The second step consists in drawing for each alternative a value from the corresponding truncated standard normal distribution of $\eta_{i t}^{2}$ using initial values of the parameters. Let us denote this value as $d_{i t}^{2}$.

The third step consists in changing from $\varepsilon_{i t}^{3}$ to $\eta_{i t}^{3}$ so that the final likelihood function becomes

$$
\begin{aligned}
& \mathcal{L}=\prod_{i, t}\left(\frac{1}{c_{33}}\right) \varphi\left(\left(T \dot{F P}_{l t}-\left(\gamma_{t}+\beta_{1}^{\prime} x_{i t}^{1}+\alpha_{12}+\beta_{2}^{\prime} x_{i t}^{2}+\left(1+c_{21}\right) d_{i t}^{1}+c_{22} d_{i t}^{2}\right)-c_{31} d_{i t}^{1}-\right.\right. \\
& \left.\left.c_{32} d_{i t}^{2}\right) / c_{33}\right) \Phi_{2}\left(d_{i t}^{1}, d_{i t}^{2}\right) \mid R(1,1) \\
& \times\left(\frac{1}{c_{33}}\right) \varphi\left(\left(T F P_{l t}-\left(\gamma_{t}+\beta_{1}^{\prime} x_{i t}^{1}+d_{i t}^{1}\right)-c_{31} d_{i t}^{1}-c_{32} d_{i t}^{2}\right) / c_{33}\right) \Phi_{2}\left(d_{i t}^{1}, d_{i t}^{2}\right) \mid R(1,0) \times \\
& \left(\frac{1}{c_{33}}\right) \varphi\left(\left(T \dot{F P} P_{l t}-\left(\gamma_{t}+\beta_{2}^{\prime} x_{i t}^{2}+c_{21} d_{i t}^{1}+c_{22} d_{i t}^{2}\right)-c_{31} d_{i t}^{1}-c_{32} d_{i t}^{2}\right) / c_{33}\right) \Phi_{2}\left(d_{i t}^{1}, d_{i t}^{2}\right) \mid R(0,1) \\
& \left.\times\left(\frac{1}{c_{33}}\right) \varphi\left(T \dot{F} P_{l t}-\gamma_{t}-c_{31} d_{i t}^{1}-c_{32} d_{i t}^{2}\right) / c_{33}\right) \Phi_{2}\left(d_{i t}^{1}, d_{i t}^{2}\right) \mid R(0,0)
\end{aligned}
$$

where $d_{i t}^{1}$ and $d_{i t}^{2}$ are draws from each of the truncated bivariate normal distributions $\Phi_{2}\left(d_{i t}^{1}, d_{i t}^{2}\right) \mid R($.$) defined over the region R($.$) , itself defined by the boundaries of \eta_{i t}^{1}$ and $\eta_{i t}^{2}$, and where $\varphi($.$) is the univariate standard normal density function, and \Phi_{2}$ the bivariate normal cumulative distribution function. It is important here to account for the Jacobian of the variable transformation $\left(\frac{1}{c_{33}}\right)$.

In our application the model has four equations, and a step is added between the second and third step above. The logic is the same but there are 8 inequalities to take into account, and 8 elements in the likelihood function. The steps are repeated 50 times and then an average is 
taken of the corresponding values of the likelihood function. ${ }^{9}$ The parameters of the likelihood function are then estimated using a numerical maximization algorithm, at each iteration repeating the simulation-based computation of the likelihood function starting from the updated values of the estimated parameters.

\footnotetext{
${ }^{9}$ Experiments with up to 200 draws did not produce very different results.
} 
Table A1. Depreciation shares in value added by industry (average across years).

10-12 Food and beverages

13-15 Textile-, leather products

0.002

0.018

16-18 Wood and paper, printing

0.003

0.008

20 Chemicals

0.004

0.006

21 Pharmaceuticals

0.002

0.091

22-23 Plastics, construction products

0.002

0.195

24-25 Basic metals and -products

0.002

0.027

26 Electronic products

0.002

0.017

27 Electric equipment

0.002

0.182

28 Machinery n.e.c.

0.003

0.211

29-30 Transport equipment

0.004

0.085

31-33 Other manufacturing, repair

0.002

0.073

58-60 Publishing, movie, radio and TV

0.003

0.016

61 Telecommunications

0.007

0.004

62-63 IT- and information services

0.016

0.005

69-71 Management, tech. consultancy

0.016

0.023

73-75 Advertising, design and other

0.007

0.011

G Wholesale and retail trade

0.008

0.010

$\mathrm{H}$ Transportation and storage

0.005

0.005

I Accommodation and food serving

0.006

0.006

0.002

0.002

Source: Statistics Netherlands, Growth accounts. 